\title{
Fructosyltransferase Activity of a Glucan-binding Protein from Streptococcus mutans
}

\author{
By R. R. B. RUSSELL, ${ }^{*}$ ANN C. DONALD† AND C. W. I. DOUGLAS \\ Dental Research Unit, Royal College of Surgeons of England, Downe, Orpington, Kent, U.K.
}

(Received 5 April 1983)

\begin{abstract}
Streptococcus mutans serotype $c$ produces several extracellular proteins which bind to affinity columns of immobilized glucans. The proteins are three distinct glucosyltransferases and another glucan-binding protein (molecular weight 74000 ) which is now shown to be a fructosyltransferase. This enzyme is antigenically distinct and genetically independent of two other fructosyltransferases produced by the same organism. A mutant is described which lacks the glucan binding fructosyltransferase and has defective ability to form adherent colonies in the presence of sucrose. Although the production of glucans from sucrose results in the glucan binding protein becoming bound to the bacterial surface, and hence perhaps contributing to adherence, the fructans synthesized by the enzyme do not appear to contribute to this phenomenon.
\end{abstract}

\section{INTRODUCTION}

The oral bacterium Streptococcus mutans secretes extracellular glucosyltransferase (GTF) and fructosyltransferase (FTF) enzymes which synthesize high molecular weight glucans and fructans from sucrose. These polymers are believed to be important components of dental plaque and to be involved in the metabolic interactions of plaque bacteria (Hamada \& Slade, 1980). Strains of $S$. mutans serotype $c$ secrete several different GTF (Kuramitsu, 1975; Mukasa et al., 1982; Russell, 1979a, 1981; Newman et al., 1980) and also three FTF of different molecular weights (Russell, 1979a, $b$ ). The GTF produce both a water-soluble dextran containing predominantly 1,6- $\alpha$-linked glucose units and a water-insoluble polymer called mutan, which is a branched glucan with both 1,6- $\alpha$ - and 1,3- $\alpha$-linkages. The FTF synthesize soluble fructans of the inulin type with predominantly 2,1- $\beta$-linked fructose units (Baird et al., 1973). Mutan appears to be particularly important in the attachment of $S$. mutans to hard surfaces; dextran mediates aggregation of the bacteria (Hamada \& Slade, 1980). There is also considerable evidence for the existence of proteinaceous dextran receptors or glucan-binding proteins at the surface of $S$. mutans which contribute to the adherence phenomenon.

Several glucan-binding proteins (GBP) have been identified by their ability to block dextranmediated agglutination (Olson, 1978) or by affinity chromatography on columns of immobilized dextran or mutan (McCabe et al., 1977; McCabe \& Hamelik, 1978; Russell, 1979c). Such affinity columns bound GTF from serotype $c$ strains as well as a GBP of estimated molecular weight 74000 (Russell, 1979c). The precise role of this GBP in adherence is as yet unknown, but recently we have demonstrated that antibody to GBP can inhibit sucrose-dependent adherence of $S$. mutans to glass surfaces (Douglas \& Russell, 1982).

$\dagger$ Present address: Beecham Pharmaceuticals Research Division, Animal Health Centre, Tadworth, Surrey KT20 7NT, U.K.

Abbreviations: FTF, fructosyltransferase; GBP, glucan-binding proteins; GTF, glucosyltransferase; PMSF, phenylmethylsulphonyl fluoride. 
In the present paper we provide evidence that GBP is a fructosyltransferase, describe a mutant lacking GBP, and report further experiments on the function of GBP in the adherence process.

\section{METHODS}

Organisms and media. Streptococcus mutans strains were as used previously (Russell, 1979d). The media used were Todd-Hewitt Broth (Oxoid) and the semi-defined medium (Cas MM) used before by Russell (1979d) but with $0.5 \%(\mathrm{w} / \mathrm{v})$ casein hydrolysate (Oxoid) instead of the individual amino acids.

Purification of $G B P$. The general procedure using affinity chromatography has been described before (Douglas \& Russell, 1982; Russell, $1979 a, c$ ). Briefly, S. mutans was grown overnight at $37^{\circ} \mathrm{C}$ in Cas MM and bacteria were removed by centrifugation and filtration. Phenylmethylsulphonyl fluoride (PMSF, $1 \mathrm{mM}$ ) was added and the filtrate was passed through a column of mutan and Sepharose. Proteins retained by the column were eluted with $6 \mathrm{M}$-guanidine. $\mathrm{HCl}$ dialysed and separated by chromatography on a column of Ultrogel AcA34 in buffer containing $0.1 \%(\mathrm{w} / \mathrm{v})$ SDS. In an alternative method, filtrate from $400 \mathrm{ml}$ Cas MM culture was brought to $45 \%$ saturation with ammonium sulphate. The precipitate which formed overnight at $4{ }^{\circ} \mathrm{C}$ was collected by centrifugation, redissolved in $4 \mathrm{ml} 0.05 \mathrm{M}-\mathrm{Tris} / \mathrm{HCl}(\mathrm{pH} 7.5)$ and dialysed for $24 \mathrm{~h}$ against the same buffer. This sample was then filtered through a column of Ultrogel AcA34 and fractions containing GBP were pooled and applied to a $0.7 \times 6.0 \mathrm{~cm}$ chromatography column containing DEAE-Trisacryl M (LKB) equilibrated with Tris buffer. Elution was with a linear gradient of 0 to $0.15 \mathrm{M}-\mathrm{NaCl}$ in Tris buffer (total volume $30 \mathrm{ml}$ ). Fractions of $1 \mathrm{ml}$ were collected and analysed for their content of GBP by SDS-PAGE, fused rocket immunoelectrophoresis or assay of enzyme activity (see below)

Immunoelectrophoretic methods. The techniques for preparation of antisera and for crossed- and fused-rocket immunoelectrophoresis and detection of GTF and FTF activity after electrophoresis have all been presented elsewhere (Russell, $1979 a, d$ ).

Enzyme assays. Release of free glucose from sucrose by FTF was assayed using a linked glucose oxidaseperoxidase assay. The reaction mixture contained $0.05 \mathrm{M}$-sodium citrate buffer $(\mathrm{pH} 6.0), 1 \%(\mathrm{w} / \mathrm{v})$ sucrose, 25 units glucose oxidase $\mathrm{ml}^{-1}$ (type X, Sigma), 25 units horseradish peroxidase $\mathrm{ml}^{-1}$ (type 11, Sigma) and $0.4 \mathrm{mg}$ $o$-phenylene diamine $\mathrm{ml}^{-1}$. To assay fractions from chromatography columns, $50 \mu \mathrm{l}$ samples were added to $200 \mu \mathrm{l}$ of reaction mixture in the wells of a microtitration tray (Sterilin) and incubated at $37^{\circ} \mathrm{C}$ for $2 \mathrm{~h}$. The absorbance at $492 \mathrm{~nm}$ was then read with the aid of an MSE Micro-ELISA plate reader. Rates of incorporation of radioactivity from ${ }^{14} \mathrm{C}$-labelled sucrose into methanol-precipitable polymer were determined by incubating enzyme samples with $0.05 \mathrm{M}$-phosphate $(\mathrm{pH} 6.5)$ containing $0.5 \%(\mathrm{w} / \mathrm{v})$ sucrose and $0.1 \mu \mathrm{Ci}(3.7 \mathrm{kBq})$ of uniformly labelled ${ }^{14} \mathrm{C}$ sucrose $\mathrm{ml}^{-1}$ (Amersham) or sucrose specifically labelled in either the glucose or fructose part of the molecule (New England Nuclear). Radioactive polymer was precipitated with ice-cold methanol and collected and washed on Whatman GF/C glass fibre filters as described by Kuramitsu (1975).

Gel electrophoresis. Proteins were separated by SDS-PAGE in slab gels of acrylamide using the buffer system of Laemmli (1970). For location of bands of enzyme activity, SDS-gels were washed in buffer and incubated with $1 \%$ $(\mathrm{w} / \mathrm{v})$ sucrose or raffinose in the presence of $1 \%(\mathrm{v} / \mathrm{v})$ Triton X-100 (Russell, 1979b).

Mutant selection. Streptococcus mutans Ingbritt was grown overnight at $37^{\circ} \mathrm{C}$ in $20 \mathrm{ml}$ Todd-Hewitt broth. The bacteria were washed twice by centrifugation in $0.1 \mathrm{M}$-phosphate buffer $(\mathrm{pH} 6.0)$ before resuspension in $20 \mathrm{ml}$ of this buffer. $N$-methyl- $N^{\prime}$-nitro- $N$-nitrosoguanidine was added to $2 \mathrm{ml}$ portions to give a concentration of $100 \mu \mathrm{g} \mathrm{ml}^{-1}$. After $30 \mathrm{~min}$ at $37^{\circ} \mathrm{C}$ the suspensions were diluted 100 -fold in Todd-Hewitt broth, incubated for $2 \mathrm{~h}$ at $37^{\circ} \mathrm{C}$, serially diluted and plated on sucrose-containing medium (TYC medium, Lab M. Ltd). Plates were incubated for $48 \mathrm{~h}$ at $37^{\circ} \mathrm{C}$ in candle jars and examined for the presence of smooth colonial variants.

Characterization of mutants. The GTF and FTF content of $S$. mutans was examined by collecting the bacteria from a $20 \mathrm{ml}$ culture grown in Todd-Hewitt broth containing $0.5 \%$ sucrose, washing them once by centrifugation in $0.9 \% \mathrm{NaCl}$ and resuspending them in $150 \mu \mathrm{l}$ of the SDS-solubilizing buffer of Laemmli (1970). After $1.5 \mathrm{~h}$ at room temperature, insoluble material was removed by centrifugation at 10000 r.p.m. for $3 \mathrm{~min}$ and the samples were applied to SDS-slab gels containing $7.5 \%$ acrylamide. After electrophoresis, zones of enzyme activity were detected as described above.

Adherence assays. The ability of wild-type and mutant strains to attach to nichrome wires was tested by a procedure based on that of McCabe et al. (1967) in which the strains were grown in Todd-Hewitt broth containing $5 \%$ sucrose. Wires embedded in rubber bungs were immersed in the culture, incubated at $37^{\circ} \mathrm{C}$, and transferred to fresh medium daily for $5 \mathrm{~d}$.

Location of GBP. The distribution of GBP between cell surface and culture supernatant was examined using the method previously described (Douglas \& Russell, 1982). Briefly, Cas MM cultures of $S$. mutans, grown for $16 \mathrm{~h}$ at $37^{\circ} \mathrm{C}$, were divided into two equal portions. One half of each culture was supplemented with sucrose, raffinose $\left(1 \%, \mathrm{w} / \mathrm{v}\right.$, final concentration), dextran T2000 or inulin (Pharmacia and BDH, respectively; $100 \mu \mathrm{g} \mathrm{ml}^{-1}$ final concentration), while no addition was made to the other half. After a further $3 \mathrm{~h}$ at $37^{\circ} \mathrm{C}$, cultures were harvested 


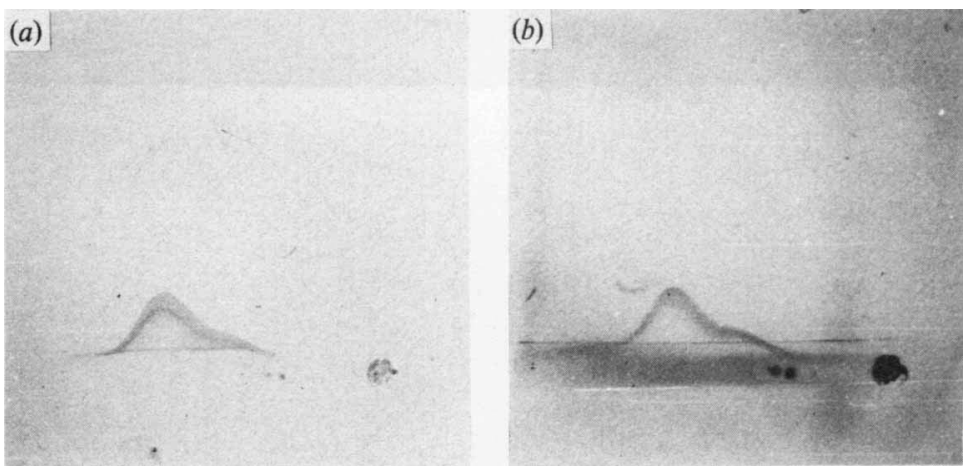

Fig. 1. Crossed immunoelectrophoresis of concentrated culture supernatant of $S$. mutans Ingbritt against antiserum to GBP. Electrophoresis was in $0.05 \mathrm{M}-\mathrm{Tris} / \mathrm{HCl}(\mathrm{pH} 7.5)$ at $5 \mathrm{~V} \mathrm{~cm}^{-1}$ for $2 \mathrm{~h}$ in the first dimension and at $1 \mathrm{~V} \mathrm{~cm}^{-1}$ for $16 \mathrm{~h}$ in the second dimension. (a) Stained with Coomassie blue (PAGE Blue 83, BDH); (b) autoradiograph of slide which had been incubated in $\left[{ }^{14} \mathrm{C}\right]$ sucrose.

by centrifugation and washed twice with phosphate-buffered saline (PBS). Cells were extracted with $6 \mathrm{M}$ guanidine. $\mathrm{HCl}$ at room temperature and culture supernatant proteins were concentrated by precipitation with ammonium sulphate. Concentrated supernatants and extracts of cells were then assayed for content of GBP by rocket immunoelectrophoresis. In some experiments this procedure was varied so that culture supernatant or bacteria were treated separately with dextran: dextran $\mathrm{T} 2000\left(100,10,1\right.$ or $\left.0 \cdot 1 \mu \mathrm{g} \mathrm{ml}^{-1}\right)$ was added to equal portions of culture supernatant and incubated for $1 \mathrm{~h}$ at room temperature before being mixed with cells. Alternatively, bacteria suspended in PBS were treated with dextran T2000 $\left(100 \mu \mathrm{g} \mathrm{ml}^{-1}\right)$ for $1 \mathrm{~h}$ at room temperature after which unbound dextran was removed by washing. The dextran-coated cells were then re-mixed with culture supernatant. In both experiments cells were extracted and supernatants concentrated as described above.

Bacterial aggregation. Bacteria which had been grown for $16 \mathrm{~h}$ at $37^{\circ} \mathrm{C}$ were washed twice and re-suspended in their original volume of Cas MM. Samples of suspension $(0.5 \mathrm{ml})$ were then mixed with $2.5 \mathrm{ml}$ fresh medium in disposable plastic-stoppered cuvettes and additions of sucrose $(0.5 \%, \mathrm{w} / \mathrm{v}$ ), dextran T2000 (Pharmacia, $\left.100 \mu \mathrm{g} \mathrm{ml}^{-1}\right)$, raffinose $\left(0.05 \%\right.$, w/v) or inulin (Sigma, $100 \mu \mathrm{g} \mathrm{ml}^{-1}$ final concentration) were made as required. The cuvettes were agitated on a spiramixer (Denley Ltd, Billingshurst, Sussex, U.K.) at $37^{\circ} \mathrm{C}$ and the extent of aggregation was estimated by monitoring the change in optical density of the samples at $550 \mathrm{~nm}$ in a Pye Unicam SP600 spectrometer.

\section{RESULTS}

\section{Purification of GTF and GBP}

The original purification of GBP involved two steps, affinity chromatography on immobilized mutan followed by gel filtration in the presence of SDS. This procedure yielded GBP which gave a single band (mol. wt 74000) on SDS-PAGE. The pure GBP was used to raise a specific rabbit antiserum; this serum precipitated a single antigen from a concentrated culture supernatant of $S$. mutans (Fig. $1 a$ ). Experiments to identify the nature of various antigens precipitated by a polyvalent antiserum in crossed immunoelectrophoresis (not shown) revealed that a peak corresponding to GBP catalysed the formation of an ethanol-precipitable polymer from ${ }^{14} \mathrm{C}$-labelled sucrose. Furthermore, autoradiography of a slide incubated in $\left[{ }^{14} \mathrm{C}\right]$ sucrose showed that a polymer was formed in the position coinciding exactly with the precipitin peak due to reaction of GBP with specific anti-GBP serum (Fig. $1 b$ ). Purified GBP was therefore reexamined for enzyme activity using ${ }^{14} \mathrm{C}$-labelled sucrose and weak activity was detected. In order to preserve this enzyme activity better during purification, a procedure which avoided the use of the strong denaturants guanidine. $\mathrm{HCl}$ and SDS was devised. Culture supernatants were brought to $45 \%$ saturation with ammonium sulphate. The major proteins precipitated were GTF and GBP; gel filtration followed by an ion-exchange chromatography step subsequently yielded GBP free of other proteins. GTF was not retarded by the DEAE-Trisacryl column but GBP was eluted at a $\mathrm{NaCl}$ concentration of approximately $0.08 \mathrm{M}$. 
(a) $\quad$ (b) $(c)$

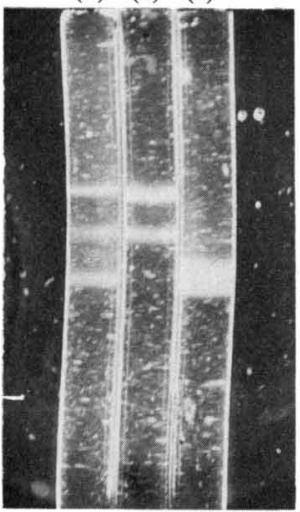

Fig. 2

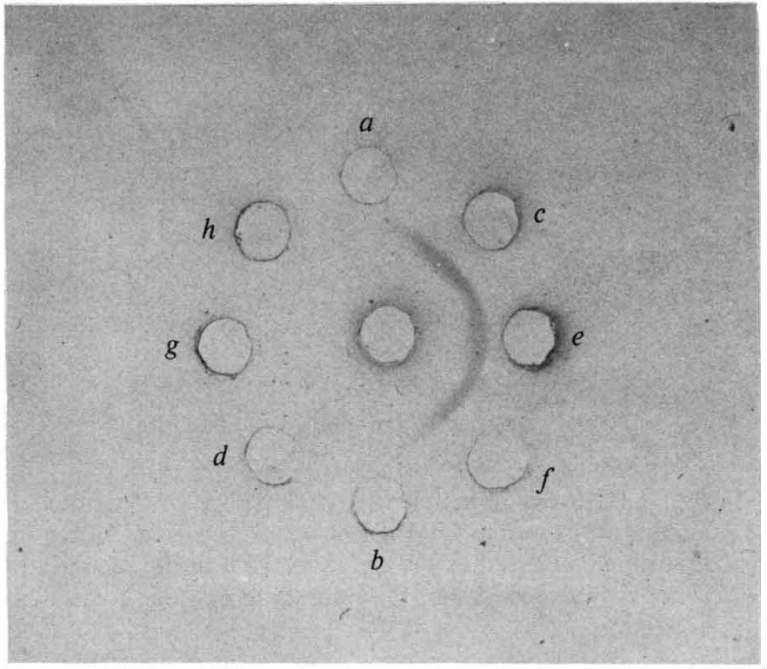

Fig. 3

Fig. 2. SDS-PAGE of supernatant proteins precipitated by $65 \%$ saturated ammonium sulphate and incubated in raffinose to reveal bands of FTF activity; (a) Ingbritt; $(b)$ NM5a; $(c)$ purified GBP.

Fig. 3. Immunodiffusion of concentrated culture supernatants of representatives of $S$. mutans serotypes against antiserum to GBP. Strains of $S$. mutans were: $a$, AHT; $b, \mathrm{FAl} ; c$, Ingbritt; $d, \mathrm{~B} 13 ; e, \mathrm{P4} ; f, 151$; $g, \mathrm{~K} 1 ; h, \mathrm{MFe} 28$.

Purified GBP retained its ability to bind to immobilized mutan and was retained by the mutan/Sepharose affinity column. It also bound to soluble dextran. When subjected to gel filtration on Ultrogel Ac34 it eluted at approximately the same point as a bovine albumin standard, indicating that it existed as a monomer. However, addition of dextran of mol. wt $2 \times 10^{6}$ (Dextran T2000, $1 \mathrm{mg} \mathrm{ml}^{-1}$ ) to GBP before gel filtration resulted in all the $\mathrm{GBP}$ emerging from the column in the excluded volume, along with the dextran.

\section{Identification of GBP as fructosyltransferase}

In order to determine whether the product formed from sucrose by GBP was a glucan or a fructan, the experiment described in Fig. $1(b)$ was repeated using sucrose specifically labelled in either the glucose or the fructose moiety. The results obtained demonstrated that only label from the fructose part of the molecule was polymerized, thus showing that GBP was a fructosyltransferase. This was confirmed by analysing the product formed by purified GBP: when hydrolysed, this yielded fructose as the sole monosaccharide detected by TLC. Furthermore, GBP could form an ethanol-precipitable polymer from raffinose, a substrate which GTF cannot utilize (Fig. 2c).

\section{Serotype distribution of $G B P$}

The presence of GBP in the various serotypes of $S$. mutans was investigated by immunodiffusion of concentrated culture supernatants against antiserum to GBP. The results (Fig. 3) showed that serotypes $c, e$ and $f$ all possessed GBP, forming a line of identity, whereas no crossreacting antigen could be detected in representatives of the other serotypes.

\section{Degradation of GBP}

It has been noted previously that in some experiments multiple bands of GBP were obtained, but that the appearance of bands of molecular weight lower than 74000 could be prevented by the protease inhibitor PMSF (Russell, 1979c, 1981). This indicated that the smaller bands were derived from the $74000 \mathrm{~mol}$. wt GBP by proteolytic degradation. In order to confirm that the smaller bands were fragments of GBP, various preparations were subjected to crossed immunoelectrophoresis with the first dimensional separation being by SDS-PAGE. The results (Fig. 4) 

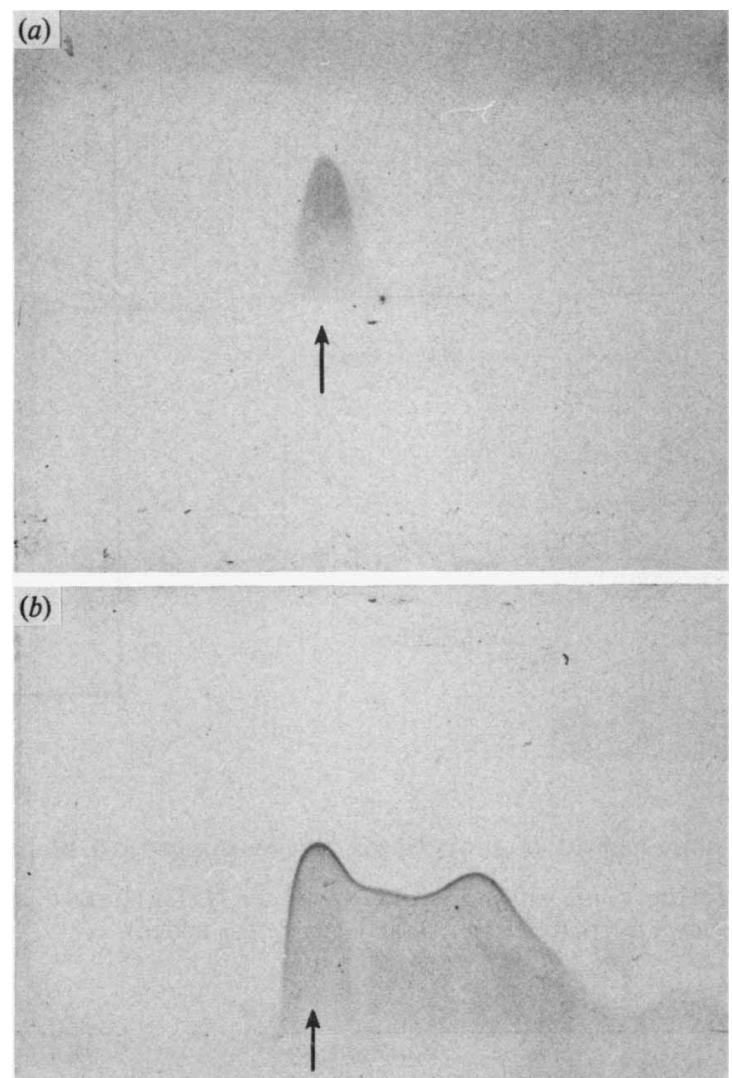

Fig. 4. Crossed immunoelectrophoresis of concentrated $S$. mutans Ingbritt culture supernatant against antiserum to GBP. The first dimension separation was by SDS-PAGE (top of gel on left). (a) Sample was prepared in the presence of $1 \mathrm{mM}-\mathrm{PMSF}$; $(b)$ no PMSF. The arrows indicate the position to which a protein of mol. wt 74000 would migrate in the first dimension.

show that the lower molecular weight forms were all antigenically related to the intact molecule, forming a single broad precipitin peak.

\section{Screening of mutants}

Approximately $1 \%$ of the colonies from the mutagen-treated culture formed smooth colonies readily distinguishable from the hard, knobbly colonies of the wild type on the sucrosecontaining TYC plates. However, many of the smooth type proved unstable and reverted to a rough morphology on restreaking. A total of 160 stable smooth mutants was examined for their content of GTF and FTF by SDS-PAGE. During our initial mutant screening we could reproducibly detect only two bands of FTF activity, mol. wt approximately 80000 and 90000 , while the occurrence of lower molecular weight bands was highly variable. With the benefit of hindsight we can explain this variability as being due to the degradation of FTF (now shown to be GBP) of mol. wt 74000 to smaller fragments. However, a total of $33(21 \%)$ of the mutants was identified as having lost one or more of the bands of enzyme activity. The mutants were also tested for their ability to adhere to nichrome wires and $27 \%$ of those examined were found to differ markedly from the wild type. Many of the mutants defective in adherence also lacked GTF and/or FTF, but eight were found which appeared to have a normal complement of enzymes yet were unable to form a coherent plaque on wires, forming instead a loose, fluffy deposit (Fig. 5). These mutants were examined for their content of GBP by rocket immunoelectrophoresis into antiserum to GBP and one, strain NM5a, was devoid of the antigen. It was also shown by SDS-PAGE that NM5a lacked the band of FTF activity corresponding to GBP in concentrated culture supernatant (Fig. $3 b$ ). 
(a)

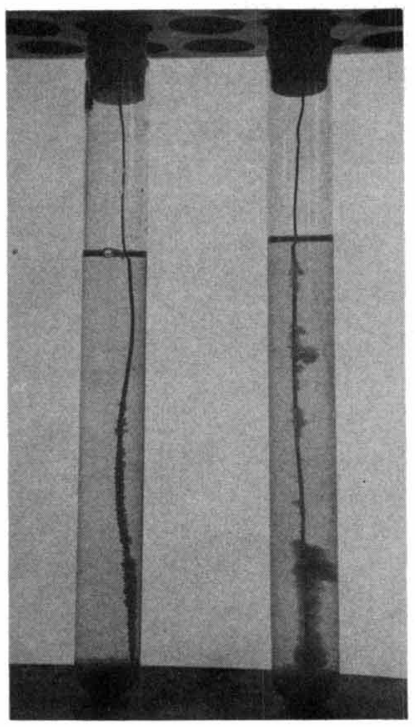

Fig. 5

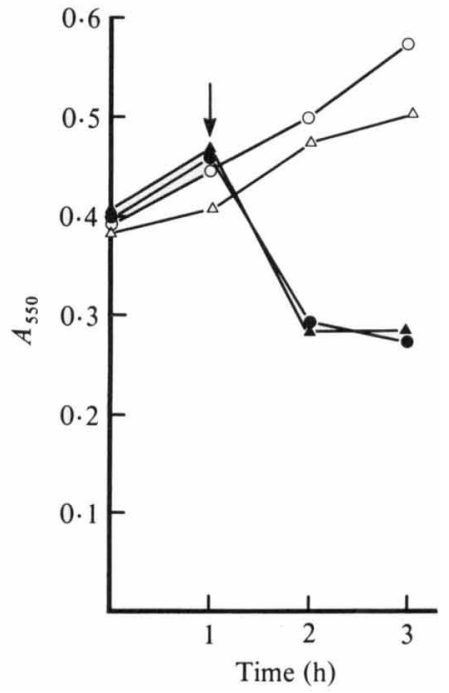

Fig. 6

Fig. 5. Growth of $(a)$ strain Ingbritt; $(b)$ strain NM5a on wires suspended in broth containing sucrose.

Fig. 6. Aggregation of cultures of $S$. mutans Ingbritt $(O, \bigcirc)$ and NM5a $(\Delta, \Delta)$ following the addition of dextran (the arrows shows the point at which the dextran was added).

\section{Aggregation}

In order to investigate the relative importance of glucans and fructans in the formation of aggregates of $S$. mutans, the optical density of cultures was monitored after the addition of sucrose (from which the bacteria synthesize dextran, mutan and fructan), raffinose (from which only fructan is made) or exogenous preformed dextran or fructan (in the form of commerciallysupplied inulin). The wild-type strain Ingbritt rapidly aggregated after the addition of sucrose or dextran (Fig. 6). Neither raffinose nor inulin caused any drop in optical density. The mutant NM5a, which lacks GBP, also aggregated in the presence of sucrose and dextran (Fig. 6), but not raffinose or inulin.

\section{Distribution of GBP between cells and culture fluid}

We have reported previously that extracellular GTF and GBP both rapidly become bound to the bacterial surface when sucrose is added to a culture (Douglas \& Russell, 1982). Extracellular and surface-bound GBP was measured by rocket immunoelectrophoresis before and after the addition of sucrose, raffinose, dextran or inulin to cultures of $S$. mutans Ingbritt. As before, sucrose caused the disappearance of GBP from the supernatant and its concomitant appearance in cell extracts. However, neither dextran, raffinose nor inulin had any effect on the location of GBP.

This result was unexpected because it had already been shown that GBP binds to dextran in solution and also that such exogenous dextran can agglutinate $S$. mutans. Therefore, the interaction between GBP, dextran and the cell surface was investigated further.

When small amounts of dextran $\left(1\right.$ and $\left.0 \cdot 1 \mu \mathrm{g} \mathrm{ml}^{-1}\right)$ were allowed to interact with GBP in the absence of cells, small amounts of GBP became associated with $S$. mutans cells added to the system. However, when the concentration of dextran was increased $\left(10\right.$ and $\left.100 \mu \mathrm{g} \mathrm{ml}^{-1}\right)$ GBP did not become cell-associated. Bacteria which had been coated with dextran before being mixed with culture supernatants did not bind GBP. 


\section{DISCUSSION}

The results presented above demonstrate that GBP has fructosyltransferase activity. In our initial report on GBP (Russell, 1979c) no activity could be detected, but the information now available indicates that this was probably due to inactivation of most of the enzyme by exposure to the denaturing agents guanidine. $\mathrm{HCl}$ and SDS. It seems probable that in many of our earlier studies GBP would also have been degraded into fragments that lacked enzyme activity (but could still bind to affinity columns) and such breakdown would also explain problems of variability in the appearance of FTF bands on the gels used to screen the mutants. A similar instability of $S$. salivarius FTF has been noted by Jacques \& Wittenberger (1981). The inclusion of the protease inhibitor PMSF prevents the breakdown of GBP and also allows the reproducible detection of GFT bands of mol. wt. 132000,140000 and 150000 as described earlier (Russell, 1981).

The introduction of DEAE-Trisacryl has provided a greatly improved method for separating GTF and GBP. The affinity of these molecules for glucans has hitherto considerably complicated schemes for their purification, as they bind in a complex manner to materials such as the dextran-based DEAE Sephadex, as well as to other chromatography column matrices (Russell, 1981).

Streptococcus mutans serotype $c$ strains possess three distinct FTF (Fig. $3 a$ and Russell, $1979 a, b)$ and the results in this paper demonstrate that the glucan-binding FTF is antigenically distinct from the other two. The loss of only one of the three FTF in mutant strain NM5a shows that it is independently determined genetically and we have recently obtained further evidence for this by cloning the gene for GBP in bacteriophage $\lambda$. The product of this gene expressed in Escherichia coli has both glucan-binding and FTF activity (Russell, Coleman \& Dougan, unpublished).

The fructans produced by $S$. mutans strains Ingbritt, JC-1 and JC-2, all of serotype $c$, have predominantly 2,1- $\beta$-linked structure like that of inulin (Baird et al., 1973; Ebisu et al., 1975; Rosell \& Birkhed, 1974). The single type of linkage found would suggest that all three FTF produce a similar product though a small amount of branching has been reported (Ebisu et al., 1975; Birkhed et al., 1979). However, only one of the three FTF has the capacity to bind to glucans. Further knowledge of the relationship between the three different FTF and their relationship to the FTF described by Carlsson (1970) must await the purification of the other two enzymes.

In a previous report (Douglas \& Russell, 1982) we have shown that extracellular GBP rapidly becomes bound to the bacterial surface when sucrose is added. The binding must be mediated by products of GTF activity, since the production of fructan from raffinose has no effect on GBP location. Although dextran or mutan synthesized by GTF caused GBP to become surfacebound, this was not found to be the case when exogenous dextran was added to a culture of $S$. mutans. This was surprising since GBP binds to soluble dextran and dextran must bind to cells in order to agglutinate them. Upon further investigation, however, we observed that some GBP would become cell-associated provided it was complexed with dextran before coming into contact with cells. GBP would not, on the other hand, bind to dextran that was already cell associated. It is possible then that GBP recognizes certain configurations or regions of glucose residues in the dextran molecule that are also recognized by a cell surface dextran receptor. It is certain that at least one other dextran receptor exists on the $S$. mutans cell surface since the mutant strain NM5a that lacks GBP still agglutinates in the presence of exogenous dextran. In addition, it has already been reported that antibody to GBP fails to inhibit dextran-mediated agglutination (Douglas \& Russell, 1982), indicating the existence of other receptor sites.

There could be advantages to the bacterium in having FTF bound to the cell in the presence of substrate, but it is not clear why only one of the three FTF should be bound. We also do not yet know what function GBP has in the adherence process - it may make a contribution to the formation of a cohesive plaque because the mutant strain lacking GBP forms only loose, fluffy deposits on wires and, as described elsewhere (Douglas \& Russell, 1982) specific antiserum to GBP inhibits attachment of $S$. mutans to glass. It is possible that the fructan product of GBP contributes to adhesiveness, but there is as yet no evidence to support this. Alternatively, the 
ability of GBP to function as an enzyme may be quite independent of its other function as a receptor or binding site for dextran or mutan: an analogous situation occurs in several carbohydrate-binding lectins from plants which recently have been shown to have enzyme activity (Dey et al., 1982; Hankins \& Shannon, 1978).

The observation that mutant strain NM5a lacks GBP and is defective in its ability to attach to wires is supportive evidence that GBP contributes to adherence but it is important to note that a number of other mutants displayed the same phenotype but still retained GBP. Our results therefore are in agreement with the observations of others, that loss of a variety of different functions can result in defective adherence (Freedman et al., 1981; Murchison et al., 1981). A complete understanding of the mechanism by which $S$. mutans adheres to teeth and contributes to the accumulation of plaque will require the identification and characterization of all these components.

\section{REFERENCES}

Baird, J. K., Longyear, V. M. C. \& Ellwood, D. C. (1973). Water insoluble and soluble glucans produced by extracellular glycosyltransferases from Streptococcus mutans. Microbios 8, 143-150.

Birkhed, D., Rosell, K.-G. \& Granath, K. (1979). Structure of water-soluble polysaccharides synthesized from sucrose by oral strains of Streptococcus mutans, Streptococcus salivarius, Streptococcus sanguis and Actinomyces viscosus. Archives of Oral Biology 24, 53-61.

Carlsson, J. (1970). A levansucrase from Streptococcus mutans. Caries Research 4, 97-113.

Dey, P. M., NaIK, S. \& Pridham, J. B. (1982). The lectin nature of $\alpha$-galactosidases from Vicia faba seeds. FEBS letters 150, 233-237.

Douglas, C. W. I. \& Russell, R. R. B. (1982). Effect of specific antisera on adherence properties of the oral bacterium Streptococcus mutans. Archives of Oral Biology 27, 1039-1045.

Ebisu, S., Kato, K., Kotani, S. \& Misaki, A. (1975). Structural differences in fructans, elaborated by Streptococcus mutans and Strep. salivarius. Journal of Biological Chemistry 78, 879-887.

Freedman, M. L., Tanzer, J. M. \& Coykendall, A. L. (1981). The use of genetic variants in the study of dental caries. In Animal Models in Cariology, pp. 247-269. Edited by J. M. Tanzer. Washington D. C. \& London: Information Retrieval Inc.

Hamada, S. \& Slade, H. D. (1980). Biology, Immunology and Cariogenicity of Streptococcus mutans. Microbiological Reviews 44, 331-384.

Hankins, C. N. \& Shannon, L. M. (1978). The physical and enzymatic properties of a phytohemagglutin from mung beans. Journal of Biological Chemistry 253, 7791-7797.

JACQUES, N. A. \& WitTenberger, C. L. (1981). Inactivation of cell-associated fructosyltransferase in Streptococcus salivarius. Journal of Bacteriology 148 , 912-918

Kuramitsu, H. K. (1975). Characterisation of extracellular glucosyltransferase activity of Streptococcus mutans. Infection and Immunity 14, 738-749.

LAEMMLI, U. K. (1970). Cleavage of structural proteins during the assembly of the head of bacteriophage T4. Nature, London 227, 680-685.

MCCabe, M. M. \& Hamelik, R. M. (1978). Multiple forms of dextran-binding proteins from Streptococ- cus mutans. In Secretory Immunity and Infection, pp. 749-759. Edited by J. R. M. MCGHEE, J. MesteCKY \& J. L. BabB. New York: Plenum Press.

MCCABE, R. M., Keyes, P. H. \& Howell, A. (1967). An in vitro method for assessing the plaque forming ability of oral bacteria. Archives of Oral Biology 12, 1653-1656.

McCabe, M. M., Hamelik, R. M. \& Smith, E. E. (1977). Purification of dextran-binding protein from cariogenic Streptococcus mutans. Biochemical and Biophysical Research Communications 78, 273-278.

Mukasa, H., Shimamura, A. \& Tsumori, H. (1982). Purification and characterization of basic glucosyltransferase from Streptococcus mutans serotype $c$. Biochimica et biophysica acta 719, 81-89.

Murchison, H., LARrimore, S. \& CURTISs, R. (1981). Isolation and characterization of Streptococcus $m u$ tans mutants defective in adherence and aggregation. Infection and Immunity 34, 1044-1055.

Newman, B. M., White, P., Mohan, S. B. \& Cole, J. A. (1980). Effect of dextran and ammonium sulphate on the reaction catalysed by a glucosyltransferase complex from Streptococcus mutans. Journal of General Microbiology 118, 353-366.

OLson, G. A. (1978). Dextran receptors as immunogens in caries prophylaxis. In Secretory Immunity and Infection, pp. 771-781. Edited by J. R. McGHEE, J. Mestecky \& J. L. BabB. New York: Plenum Press.

Rosell, K.-G. \& BIRKhed, D. (1974). An inulin-like fructan produced by Streptococcus mutans, strain JC2. Acta chemica scandinavia 5, 589.

Russell, R. R. B. (1979a). Glycosyltransferases of Streptococcus mutans strain Ingbritt. Microbios 23, 135-146.

Russell, R. R. B. $(1979 b)$. Use of Triton X-100 to overcome the inhibition of fructosyltransferase by SDS. Analytical Biochemistry 97, 173-175.

RUSSELL, R. R. B. (1979c). Glucan-binding proteins of Streptococcus mutans serotype c. Journal of General Microbiology 112, 197-201.

Russeli, R. R. B. $(1979 d)$. Wall-associated protein antigens of Streptococcus mutans. Journal of General Microbiology 114, 109-115.

Russell, R. R. B. (1981). Non-specific binding of Streptococcus mutans glucan-binding proteins and lipoteichoic acid to immunosorbent columns. FEMS Microbiology Letters 11, 279-282. 